\title{
Ganoderma lucidum Prevents Cisplatin-Induced Nephrotoxicity through Inhibition of Epidermal Growth Factor Receptor Signaling and Autophagy-Mediated Apoptosis
}

\author{
Yasmen F. Mahran $\mathbb{D D}^{1,2}$ and Hanan M. Hassan ${ }^{3}$ \\ ${ }^{1}$ Department of Pharmaceutical Sciences, Faculty of Pharmacy, Princess Nourah bint Abdulrahman University, Riyadh, Saudi Arabia \\ ${ }^{2}$ Department of Pharmacology \& Toxicology, Faculty of Pharmacy, Ain Shams University, Cairo, Egypt \\ ${ }^{3}$ Department of Biochemistry, Faculty of Pharmacy, Delta University for Science and Technology, International Coastal Road, \\ Gamasa City, Egypt
}

Correspondence should be addressed to Yasmen F. Mahran; jassie_81@hotmail.com

Received 26 March 2020; Revised 16 May 2020; Accepted 2 June 2020; Published 6 July 2020

Guest Editor: Felipe L. de Oliveira

Copyright (c) 2020 Yasmen F. Mahran and Hanan M. Hassan. This is an open access article distributed under the Creative Commons Attribution License, which permits unrestricted use, distribution, and reproduction in any medium, provided the original work is properly cited.

\begin{abstract}
Background. Cisplatin (cis-diaminedichloroplatinum, CDDP) is a broad-spectrum antineoplastic agent. However, CDDP has been blamed for its nephrotoxicity, which is the main dose-limiting adverse effect. Ganoderma lucidum (GL), a medicinal mushroom, has antioxidant and inflammatory activities. Therefore, this study is aimed at finding out the potential nephroprotection of GL against CDDP-induced nephrotoxicity in rats and the possible molecular mechanisms including the EGFR downstream signaling, apoptosis, and autophagy. Methods. Rats were given GL (500 mg/kg) for 10 days and a single injection of CDDP $(12 \mathrm{mg} / \mathrm{kg}$, i.p). Results. Nephrotoxicity was evidenced by a significant increase in renal indices and oxidative stress markers. Additionally, CDDP showed a plethora of inflammatory and apoptotic responses as evidenced by a profound increase of HMGB-1, NF- $\kappa \mathrm{B}$, and caspase-3 expressions, whereas administration of GL significantly improved all these indices as well as the histopathological insults. Renal expression of EGFR showed a similar trend after GL administration. Furthermore, activation of autophagy protein, LC3 II, was found to be involved in GL-mediated nephroprotection correlated with the downregulation of apoptotic signaling, caspase- 3 and terminal deoxynucleotidyl transferase (TDT) renal expressions. Conclusion. These results suggest that GL might have improved CDDP-induced nephrotoxicity through antioxidant, anti-inflammatory, and autophagy-mediated apoptosis mechanisms and that inhibition of EGFR signaling might be involved in nephroprotection.
\end{abstract}

\section{Introduction}

Cisplatin (cis-diaminedichloroplatinum, CDDP) is a frontline broad-spectrum antineoplastic agent [1]. It is widely used in clinical practice against various solid tumors such as head and neck cancer [2], ovarian cancer [3], bladder cancer [4], and breast cancer [5]. The anticancer action of CDDP is predominantly mediated via the formation of DNA adducts that activate various signaling mechanisms including cell cycle arrest and apoptosis [6]. However, albeit its effectiveness, CDDP has been blamed for its nephrotoxicity, the main dose-limiting adverse effect, seen in approximately one-third of the patients $[7,8]$. Nephrotoxicity is elaborated by ample manifestations such as increased serum creatinine as well as blood urea nitrogen (BUN) levels and decreased renal blood flow, which reflects tubular dysfunction $[9,10]$. Moreover, several mechanisms are involved in nephrotoxicity induced by CDDP such as the formation of toxic DNA adducts, lipid peroxidation, and depletion of reduced glutathione (GSH) $[11,12]$. These events cause necrosis and mitochondrial vacuolization in renal proximal tubular cells, which are known to accumulate a high amount of CDDP [6]. It was reported that necrotic tubular cells release highmobility group box-1 (HMGB-1), which induces further 
inflammatory response through activation of nuclear factor kappa $\mathrm{B}(\mathrm{NF}-\kappa \mathrm{B})$ [13] leading to acute kidney injury (AKI) $[14,15]$. Therefore, suppressing the oxidative and inflammatory-mediated tubular cell death is considered a good promising approach to prevent and treat CDDPinduced nephrotoxicity. Although tremendous approaches have been investigated for alleviating CDDP-induced nephrotoxicity, none of these approaches did completely and successfully protect the kidneys $[13,16]$. Therefore, it is still necessary to identify novel effective strategies to minimize the renal cytotoxicity of CDDP. Of all these approaches used, natural compounds have been shown to provide promising protection [17-19].

Ganoderma lucidum (GL), a functional medicine and food, is one of the most highly regarded traditional Chinese medicines due to its ability to strengthen human health [20]. Modern pharmacological and clinical investigations have demonstrated that GL has multifarious pharmacological properties, such as antibacterial [21], antioxidant [22], and anti-inflammatory effects in different in vivo models $[23,24]$ in addition to its hepatoprotective and antitumor properties [25]. Indeed, GL possesses a wide variety of bioactive molecules like terpenoids, phenolic compounds, and polysaccharides, which have attracted attention in recent years due to their extensive antioxidation and anti-inflammation [22, 26, 27]. Some studies have shown that GL could protect the kidney against different models of acute nephropathy such as ischemiareperfusion injury [28], diabetic nephropathy [29], and adriamycin-induced nephropathy [30]. Moreover, one study reported that GL terpenes protected against CDDP-induced nephrotoxicity through antioxidative effect; however, the mechanisms underlying this protection were not fully elucidated and still unclear [31]. Therefore, elaborating the mechanisms by which GL may protect CDDP renal injury is highly needed.

Indeed, ample pieces of evidence had explored the involvement of multiple cell death and survival pathways in CDDP nephrotoxicity [32]. However, the mechanisms involved in these pathways are controversial. Some studies reported the prosurvival role of autophagy in nephrotoxic models of CDDP [33], while Wada and his coworkers [34] suggested that erlotinib could ameliorate CDDP nephrotoxicity via inhibition of the epidermal growth factor (EGFR)/AKT downstream signaling pathway, which has a potential regulatory effect on autophagy [35]. Moreover, it is promising to find that ganoderic acid could target the EGFR downstream signaling transduction [36, 37]. Further elucidation of different interrelated signaling pathways involved in the CDDP-induced nephrotoxicity amendment is highly warranted. Consequently, this present study was conducted to find answers to the following questions. (1) Does GL produce significant nephroprotection against CDDP-induced nephrotoxicity in rats? (2) If so, what are the possible molecular mechanisms underlying this nephroprotective effect? (3) Is the autophagy/apoptosis interrelation involved in GL promising protection? (4) Does EGFR signaling contribute in GL nephroprotection?

\section{Materials and Methods}

2.1. Materials. Ganoderma lucidum was purchased from DXN Pharmaceutical SDN (BHD, Malaysia). CDDP was obtained from (Sigma Chemical Co., St. Louis, MO, USA). All other chemicals and solvents were of the highest grade commercially available.

\subsection{Assessment of Total Phenolic Content, Total Flavonoid} Content, and Total Antioxidant Capacities of GL Powder. Total phenolic content (TPC) was determined according to Folin-Ciocalteu reagent method reported by Lin et al. [38]. First, $0.1 \mathrm{ml}$ aliquots of the GL in distilled water $(0.1 \mathrm{~g} / \mathrm{ml})$ were mixed with $2.8 \mathrm{ml}$ of distilled water, $2 \mathrm{ml}$ of $2 \%(w / v)$ sodium carbonate, and $0.1 \mathrm{ml}$ of $50 \%(\mathrm{v} / \mathrm{v})$ of Folin-Ciocalteu reagent. Then, the obtained mixture was incubated at room temperature for half an hour and the absorbance was measured against distilled water at $750 \mathrm{~nm}$, using a standard curve of gallic acid (0-200 mg/l). TPC value was expressed as milligram gallic acid equivalent (GAE)/g based on the dry weight. Results showed $133 \mathrm{mg}$ GAE/g of GL powder.

Total flavonoid content (TFC) of GL powder was determined using aluminum chloride method which was described by Chang and coworkers [39], and the value was expressed as milligram quercetin equivalent (QE)/g based on the dry weight. Results showed $24 \mathrm{mg} \mathrm{QE} / \mathrm{g}$ of GL powder.

Total antioxidant capacity of GL powder was evaluated using 2,20-azino-bis (3-ethyl benzothiazoline-6-sulfonic acid) (ABTS) assay method reported by Lissi et al. ABTS free radical-scavenging capacity of GL solution $(1 \mathrm{mg} / \mathrm{ml})$ was measured and expressed as percentage inhibition using ascorbic acid $(20 \mu \mathrm{l}, 2 \mathrm{mM})$ solution as a standard antioxidant (positive control). GL showed a percentage inhibition of $58 \%$ against $88 \%$ of ascorbic acids [40].

2.3. Animals. The study was conducted according to ethical guidelines of the Ethical Committee of the Faculty of Pharmacy, University of Delta for Sciences and Technology Gamasa City, Egypt, approval number FPDU1/2020. The Guidelines for the Care and Use of Laboratory Animals declared by the National Institutes of Health (NIH) were followed in all the experimental procedures. Adult male Sprague-Dawley rats (weighing 120-240 g) were obtained from the Experimental Animal Center, Mansoura University, and housed under standard light conditions (12 h light/12 h dark) with food and water available ad libitum for all rats. Standard diet pellets contained not less than $20 \%$ protein, $5 \%$ fiber, $3.5 \%$ fat, $6.5 \%$ ash, and a vitamin mixture according to the standard guidelines.

2.4. Experimental Design. Rats were randomly classified into six groups (eight rats per group) $(n=8)$ and were injected as follows. (1) Control group: rats received distilled water (1000 mg/dl) daily for 10 days using oral gavage. (2) GL alone group: rats received $G L(500 \mathrm{mg} / \mathrm{kg} /$ day $)$ in distilled water (1000 mg/dl) daily for 10 days using oral gavage. (3) Cisplatin group: rats were injected with CDDP (12 mg/kg b.w, i.p) single dose on day 3. (4) CDDP+GL daily group: rats received oral $G L(500 \mathrm{mg} / \mathrm{kg} /$ day $)$ in distilled water daily for 10 days starting 3 days before CDDP injection $(12 \mathrm{mg} / \mathrm{kg}$ b.w, i.p) 
single dose on day 3. (5) CDDP+GL every other day (EOD) group: rats received oral GL $(500 \mathrm{mg} / \mathrm{kg} /$ day $)$ in distilled water every other day for 10 days starting 3 days before CDDP injection $(12 \mathrm{mg} / \mathrm{kg}$ b.w, i.p) single dose on day 3 .

(6) $\mathrm{CDDP}+\mathrm{GL}$ inject. group: rats were injected with $G L$ $(500 \mathrm{mg} / \mathrm{kg} /$ day i.p) twice on days 2 and 6 starting 1 day before CDDP injection $(12 \mathrm{mg} / \mathrm{kg}$ b.w, i.p) single dose on day 3.

Cisplatin was given as a single dose of $12 \mathrm{mg} / \mathrm{kg}$ intraperitoneally according to previous studies [41]. Also, GL doses were chosen according to previous studies [42-44]. Also, pilot experimental trials were carried out for the same purpose. Seven days post-CDDP injection (on day 10), rats were fasted for 12 hours and sacrificed by cervical dislocation. Blood serum was separated by centrifugation at $3000 \mathrm{rpm}$ for $5 \mathrm{~min}$ and stored at $-80^{\circ} \mathrm{C}$ for biochemical assessment. Kidney tissues were quickly harvested, and one part was instantly fixed in 10\% phosphate-buffered formaldehyde for histological and immunohistochemical studies. Moreover, kidney samples were homogenized at $1: 10(w: v)$ in $0.1 \mathrm{M}$ phosphate buffer ( $\mathrm{pH}$ 7.4) with an Ultra Turrax Homogenizer and kept frozen at $-80^{\circ} \mathrm{C}$ for antioxidant, anti-inflammatory, and apoptotic markers.

2.5. Histopathological Examination and Tubular Injury Score. Samples of kidney tissues of different groups were fixed in $4 \%$ paraformaldehyde for 72 hours and embedded in paraffin wax, and 3-4 $\mu \mathrm{m}$ slices from the prepared paraffin blocks were stained with hematoxylin-eosin (H\&E) for histopathological inspection using light microscopy according to a previous method [45]. Also, a semiquantitative scoring of the percentage of pathological injury area under a single field of vision was done and the scoring criteria was used as described previously $[46,47]$ : the injury area is $0 \%, 0$ points, normal; injury area $<25 \%, 1$ point, mild; injury area is 25 $50 \%, 2$ points, moderate; injury area is $50-75 \%, 3$ points, severe; and injury area $>75 \%$, 4 points, extremely severe.

2.6. Assessment of Renal Function Markers. Renal function markers such as BUN and serum creatinine levels were assessed colorimetrically using the commercially available kits; Biodiagnostic Assay Kit (Cairo, Egypt). Blood urea nitrogen was measured colorimetrically at $578 \mathrm{~nm}$ according to the previous method of Chaney and Marbach [48]. Serum creatinine was determined by measuring the colored complex formed by the reaction of creatinine with picrate in an alkaline medium colorimetrically at $520 \mathrm{~nm}$ according to the previous method by Schirmeister and his colleagues [49].

2.7. Assessment of Oxidative Stress Markers. To assess the renal oxidant status, hydrogen peroxide $\left(\mathrm{H}_{2} \mathrm{O}_{2}\right)$ was assayed colorimetrically at $510 \mathrm{~nm}$ according to the method of Aebi [50]. Also, the activity of superoxide dismutase (SOD) in tissue homogenates of different groups was assessed spectrophotometrically at $412 \mathrm{~nm}$ using the method of DeChatelet and colleagues [51].

2.8. Assessment of Inflammatory and Apoptotic Markers. Renal HMGB-1 was assessed as previously described [52], using ELISA kits (Bioassay Technology Laboratory, Shang- hai, China) exactly following the manufacturers' instructions. In addition, the NF- $\kappa \mathrm{B}$ assay kit (MyBioSource, Inc., San Diego, USA) was used to determine the renal NF- $\kappa$ B expression. Caspase- 3 was also assessed using assay kits (BioVision Inc., Milpitas, USA), according to the manufacturers' instructions.

2.9. Assessment of Autophagy-Related Protein, LC3 II, Using Flow Cytometry. Intracellular content of the autophagy protein, microtubule-associated protein 1A/1B-light chain 3 (LC3 II), was evaluated by flow cytometric analysis using the method of Shvets and his coworkers [53, 54]. Briefly, suspensions of cells were prepared in phosphate-buffered saline/bovine serum albumin (PBS/BSA) buffer and then incubated with anti-LC3 fluorescein isothiocyanate for $30 \mathrm{~min}$ at room temperature. Cells were then washed using $\mathrm{PBA} / \mathrm{BSA}$, centrifuged at $400 \times \mathrm{g}$ for 5 minutes, resuspended in $0.5 \%$ paraformaldehyde in PBS/BSA, and then analyzed using flow cytometry. The fluorescence-activated cell sorter (FACS) used is Becton Dickinson Accuri C6 (BD Accuri C6). The flow cytometer system is equipped with an argonion laser emitting at $488 \mathrm{~nm}$. Data were analyzed using CellQuest software (Becton Dickinson).

2.10. Immunohistochemical Detection of Growth Factor, the Epidermal Growth Factor Receptor (EGFR), and Terminal Deoxynucleotidyl Transferase (TDT). $3 \mu \mathrm{m}$ thick renal sections of different groups were submerged in peroxidase for 10 minutes and washed. Then, the sections were immunostained with the primary rabbit polyclonal antibody to rat EGFR and terminal deoxynucleotidyl transferase (TDT) (Abcam, USA) at a concentration of $1 \mu \mathrm{g} / \mathrm{ml}$ and incubated overnight at $4^{\circ} \mathrm{C}$. After washing the slides with Trisbuffered saline, $100 \mu \mathrm{l}$ of poly-horseradish peroxidase (HRP) (Genemed Power-Stain 1.0 Poly HRP DAB) kits was added, incubated for 15 minutes, and rinsed 3 times with wash buffer for 2 minutes. The substrate solution was prepared by mixing diaminobenzidine (DAB) chromogen with DAB buffer solution, and then, it was added on slides and incubated for 5-10 minutes at room temperature. Slides were rinsed with tap water and counterstained with hematoxylin according to the manufacturer's instruction. Additionally, area \% of immunoexpression levels of EGFR and TDT in kidney tissues was determined in 6 random fields per group using the Leica Application module attached to Full HD microscopic imaging system (Leica Microsystems $\mathrm{GmbH}$, Germany).

2.11. Statistical Analysis. Data were expressed as the mean \pm SEM. Multiple group comparisons among different groups were attained using one-way ANOVA followed by TukeyKramer as a post hoc test, as appropriate. $P$ values $<0.05$ were considered statistically significant. InStat ver. 3 software package was utilized for statistical analyses, and graphs were created by GraphPad Prism ver. 5 software (USA).

\section{Results}

3.1. GL Ameliorated Cisplatin-Induced Nephrotoxicity. To confirm the protective effect of GL on acute nephrotoxicity 


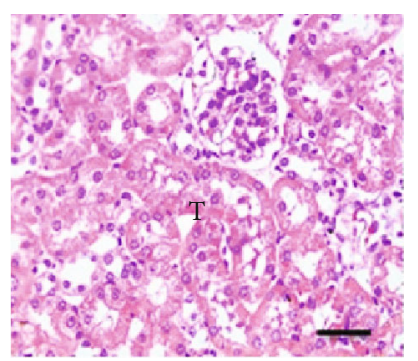

(a)

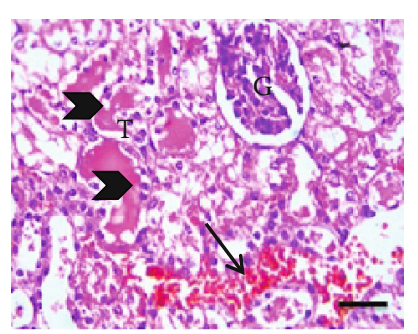

(d)

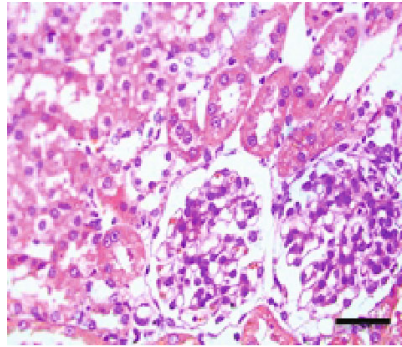

(b)

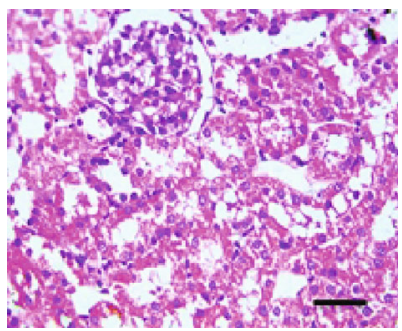

(e)

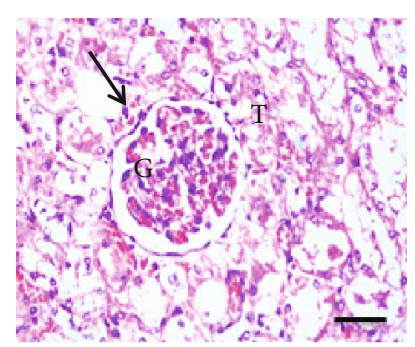

(c)

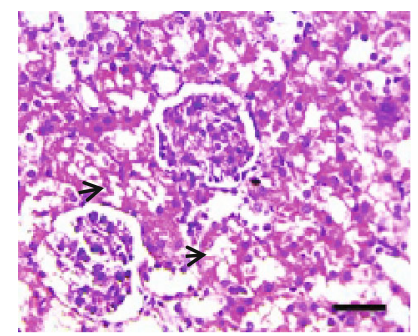

(f)

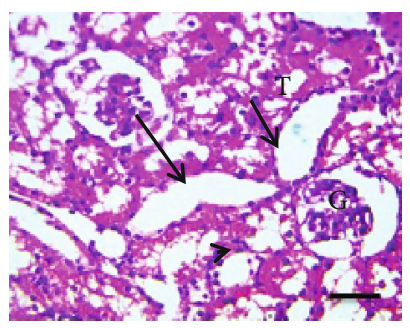

(g)

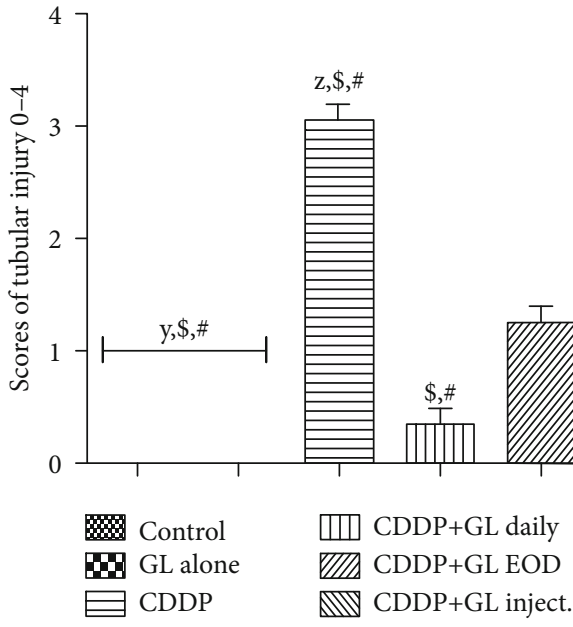

(h)

Figure 1: Photomicrographs of kidney sections stained with hematoxylin and eosin. $(a, b)$ Control and G. lucidum groups show normal histology of glomeruli $(\mathrm{G})$ and tubules $(\mathrm{T})$. (c, d) The cisplatin group shows congested glomeruli and renal tubules (black arrow), severe tubular dilation, perivascular lymphocytic cell infiltration $(G)$, and tubular cast formation (arrowheads). (e) The CDDP+GL daily group shows restored histological picture of the kidney. (f) The CDDP+GL EOD group shows mild vacuolar degeneration in epithelial lining renal tubules (short black arrows). (g) The CDDP+GL inject. group shows edematous swelling of Bowman's capsule of glomeruli (G), tubular dilation (long black arrows) with vacuolar degeneration in epithelial lining renal tubules (short black arrows) (T). X: 400 bar 50. (h) Statistical analysis of tubular injury scores; values are mean \pm SEM $(n=10)$. ${ }^{\mathrm{x}} P<0.05$ compared to the control group, ${ }^{\mathrm{y}} P<0.05$ compared to the CDDP group, ${ }^{\mathrm{z}} P<0.05$ compared to the CDDP+GL daily, ${ }^{\$} P<0.05$ compared to the CDDP+GL EOD group, and ${ }^{\#} P<0.05$ compared to the CDDP+GL inject. group using one-way ANOVA followed by Tukey-Kramer as post hoc test. CDDP: cisplatin; GL: Ganoderma lucidum; EOD: every other day.

induced after CDDP, histopathological evaluation, as well as biochemical renal function indices, was carried out. Compared to the control or GL alone groups, H\&E-stained kidney tissues of the CDDP group displayed massive tubular damage (showing a tubular injury score of $3 \pm 0.15$ ) including tubular dilatation, epithelial degeneration and necrosis, congestion of renal blood vessels, tubular cast formation, and perivascular lymphocytic cell infiltration (Figures 1(c), 1(d), and 1(h)). Interestingly, the tubular injury was significantly restored after GL administration daily as well as EOD showing a score of $0.35 \pm 0.1$ and $1.25 \pm 0.16$, respectively, with some mild vacuolar degeneration in epithelial lining renal tubules in the EOD group (Figures 1(e), 1(f), and 1(h)). However, in Figures $1(\mathrm{~g})$ and $1(\mathrm{~h})$, the photomicrograph of the GL inject. group shows edematous swelling of Bowman's capsule of glomeruli, tubular dilation with mild vacuolar degeneration in epithelial lining renal tubules, and a tubular injury score of $1.7 \pm 0.21$

At the end of the experiment, on day 10, CDDP induced a distinct rise in both BUN and creatinine levels, about 5.4- 
TABLE 1: Effects of cisplatin and Ganoderma lucidum on nephrotoxicity indices, oxidative stress, and inflammatory markers in kidney tissues of rats.

\begin{tabular}{lccccc}
\hline & $\mathrm{BUN}(\mathrm{mg} / \mathrm{dl})$ & Serum creatinine $(\mathrm{mg} / \mathrm{dl})$ & $\mathrm{SOD}(\mathrm{ng} / \mathrm{mg}$ protein) & $\mathrm{H}_{2} \mathrm{O}_{2}(\mathrm{ng} / \mathrm{mg}$ protein) & HMGB-1 (pg/mg protein) \\
\hline Control & $13.10 \pm 1.30$ & $0.32 \pm 0.02^{\mathrm{y}, \$, \#}$ & $144.20 \pm 2.40^{\mathrm{y}, \#}$ & $0.15 \pm 0.01^{\mathrm{y}}$ & $4.40 \pm 0.11^{\mathrm{y}, \mathrm{z}, \$, \#}$ \\
& $12.12 \pm 0.65$ & $0.31 \pm 0.02^{\mathrm{y}, \$, \#}$ & $145.68 \pm 0.38^{\mathrm{y}}$ & $0.16 \pm 0.01^{\mathrm{y}}$ & $5.06 \pm 0.09^{\mathrm{y}, \$, \#}$ \\
GL alone & $\mathrm{y}, \mathrm{z}, \$$ & $1.2 \pm 0.10^{\mathrm{z}, \$, \#}$ & $100.90 \pm 9.21^{\mathrm{z}, \$, \#}$ & $0.29 \pm 0.02^{\mathrm{z}, \$, \#}$ & $7.40 \pm 0.14^{\mathrm{z}, \$}$ \\
CDDP & $71.24 \pm 1.52^{\mathrm{z}, \$, \#}$ & $0.41 \pm 0.02^{\$, \#}$ & $151.07 \pm 1.91$ & $0.17 \pm 0.01$ & $5.42 \pm 0.14^{\$, \#}$ \\
CDDP+GL daily & $37.79 \pm 1.87^{\$, \#}$ & $0.84 \pm 0.06$ & $138.75 \pm 5.93$ & $0.19 \pm 0.01$ & $6.51 \pm 0.24$ \\
CDDP+GL EOD & $62.17 \pm 1.52$ & $0.88 \pm 0.09$ & $129.28 \pm 7.63$ & $0.20 \pm 0.01$ & $6.64 \pm 0.17$ \\
CDDP+GL inject. & $64.55 \pm 1.24$ & & & \\
\hline
\end{tabular}

Values are mean $\pm \operatorname{SEM}(n=5) .{ }^{\mathrm{X}} P<0.05$ compared to the control group, ${ }^{\mathrm{y}} P<0.05$ compared to the CDDP group, ${ }^{\mathrm{z}} P<0.05$ compared to the CDDP+GL daily group, ${ }^{\$} P<0.05$ compared to the CDDP+GL EOD group, and ${ }^{\#} P<0.05$ compared to the CDDP+GL inject. group using one-way ANOVA followed by TukeyKramer as post hoc test. CDDP: cisplatin; GL: Ganoderma lucidum; EOD: every other day; BUN: blood urea nitrogen; SOD: superoxide dismutase; $\mathrm{H}_{2} \mathrm{O}_{2}$; hydrogen peroxide; HMGB-1: high-mobility group box-1.

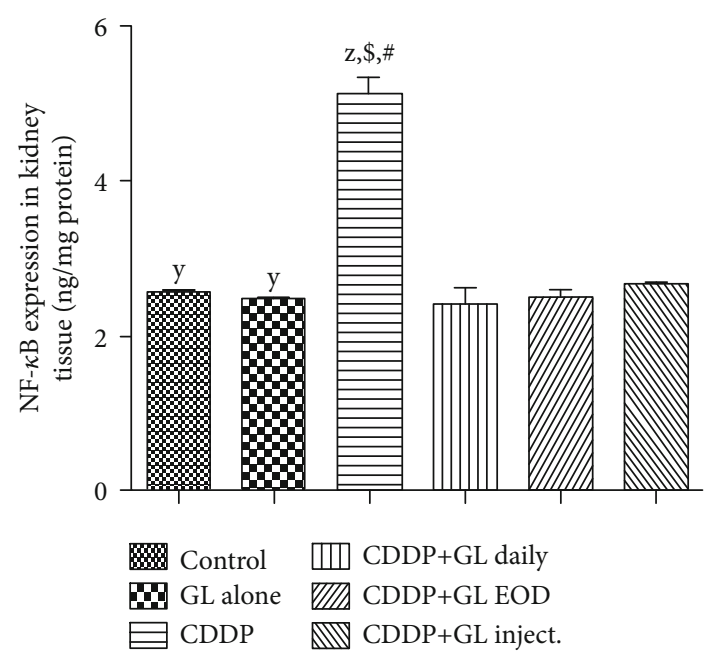

Figure 2: Effects of cisplatin and Ganoderma lucidum on the expression of nuclear factor-kappa B (NF- $\kappa$ B) in kidney tissues of rats. Values are mean $\pm \operatorname{SEM}(n=5) .{ }^{X_{P}<0.05}$ compared to the control group, ${ }^{\mathrm{y}} P<0.05$ compared to the CDDP group, ${ }^{\mathrm{z}} \mathrm{P}<0.05$ compared to the CDDP+GL daily group, ${ }^{\$} P<0.05$ compared to the CDDP+GL EOD group, and ${ }^{\#} P<0.05$ compared to the CDDP + GL inject. group using one-way ANOVA followed by TukeyKramer as post hoc test. CDDP: cisplatin; GL: Ganoderma lucidum; EOD: every other day; NF- $\kappa$ B: nuclear factor kappa B.

and 3.8-fold as compared to the control group (Table 1). However, GL administration showed a considerable reduction in BUN levels by about $47.8 \%$ for the CDDP+GL daily group, $12 \%$ for the CDDP+GL EOD oral administration group, and only $9.8 \%$ for the $\mathrm{CDDP}+\mathrm{GL}$ inject. group. On the other hand, the elevation of serum creatinine was significantly reduced after GL treatment, which was consistent with histologic improvement. The GL oral EOD and IP administration decreased serum creatinine to about $70 \%$ and $73 \%$ of the CDDP group while the CDDP+GL daily group nearly normalized serum creatinine level, $34 \%$ of the CDDP group (Table 1). Furthermore, the administration of GL alone caused no significant morphologic or biochemical alterations in renal function tests.
3.2. GL Reduced the Cisplatin-Induced Oxidative Stress. As shown in Table 1, kidney tissues of the CDDP group showed distinct oxidative stress that was evidenced by 0.69 -fold depletion of the antioxidant enzyme, SOD, as well as a 1.8fold increment in $\mathrm{H}_{2} \mathrm{O}_{2}$ renal levels as compared to the control group. Nonetheless, GL significantly counteracted the oxidative stress induced by CDDP as it upregulated the SOD levels and downregulated the $\mathrm{H}_{2} \mathrm{O}_{2}$ levels when compared to the CDDP group. Also, the CDDP+GL daily group showed the highest level of amelioration (reaching about $151 \%$ and $58 \%$ of the CDDP group) for SOD and $\mathrm{H}_{2} \mathrm{O}_{2}$, respectively. Furthermore, no significant variations have been found in the GL alone group when compared to the control group.

3.3. GL Decreased the Cisplatin-Mediated Inflammatory Signaling. Inflammatory markers have been assessed using the ELISA technique for HMGB- 1 and NF- $\kappa$ B expressions in kidney homogenates of different groups. At the end of the experiment, renal HMGB-1 (Table 1), as well as NF- $\kappa$ B (Figure 2) expressions, showed a significant upregulation in CDDP-injected rats as compared to the control group, while GL administration significantly ameliorated the CDDPinduced inflammation in terms of HMGB-1 as evidenced by $27 \%, 12.2 \%$, and $10 \%$ reduction for the $\mathrm{CDDP}+\mathrm{GL}$ daily, $\mathrm{CDDP}+\mathrm{EOD}$, and $\mathrm{CDDP}+\mathrm{GL}$ inject. groups, respectively, being CDDP+GL daily having the lowest level of HMGB-1 when compared to the CDDP group (Table 1). Moreover, GL administration of different groups nearly normalized NF- $\kappa \mathrm{B}$ expressions in the kidneys when compared to the CDDP group. However, GL alone showed nonsignificant values for HMGB-1 and NF- $\kappa$ B when compared to the control values (Table 1 and Figure 2).

3.4. The Apoptotic Pathway Involved in GL's Renoprotection against Cisplatin. One of the crucial cellular responses to kidney damage is renal cell apoptosis particularly in CDDPinduced AKI [6]. The proapoptotic caspase-3 expression levels as well as TDT have been determined to evaluate the antiapoptotic effect of GL treatment in CDDP-injured rats (Figures 3 and 4). Regarding caspase-3 expression, an intense 


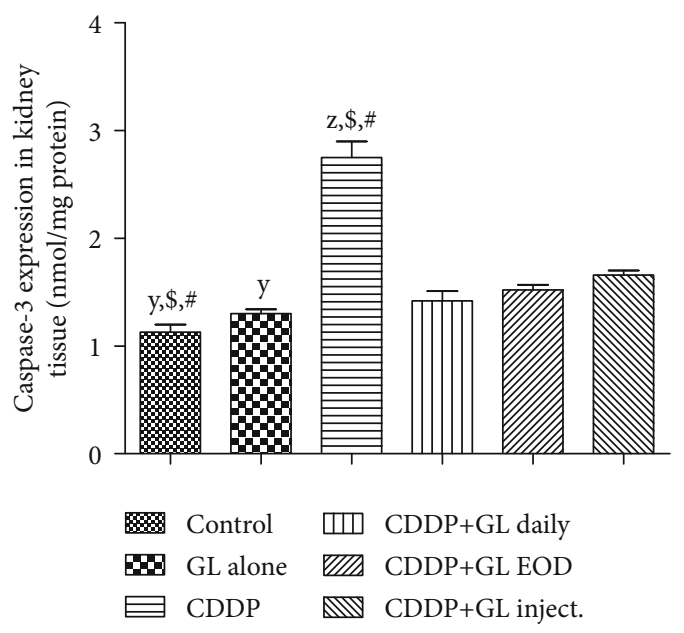

FIgURE 3: Effects of cisplatin and Ganoderma lucidum on the expression of caspase- 3 in kidney tissues of rats. Values are mean \pm SEM $(n=5) .{ }^{x_{P}<0.05}$ compared to the control group, ${ }^{\mathrm{y}} \mathrm{P}<0.05$ compared to the CDDP group, ${ }^{\mathrm{z}} \mathrm{P}<0.05$ compared to the CDDP+GL daily group, ${ }^{\$} P<0.05$ compared to the CDDP+GL EOD group, and ${ }^{\#} P<0.05$ compared to the CDDP+GL inject. group using one-way ANOVA followed by Tukey-Kramer as post hoc test. CDDP: cisplatin; GL: Ganoderma lucidum; EOD: every other day.

upregulation in CDDP-injected rat kidneys, 2.4-fold of the control group, was detected (Figure 3). After GL administration, caspase-3 expression levels significantly decreased (reaching about 0.5-, 0.55-, and 0.66-fold of the CDDP group) in the daily, EOD, and inject. groups, respectively. Moreover, the results from TDT assay confirmed that CDDP could induce extensive renal cell apoptosis (Figure 4(c)); nevertheless, treatment with GL greatly reduced the number of TDT-positive apoptotic cells which confirmed that GL mitigated the CDDP-induced tubular cell apoptosis as shown in Figures $4(\mathrm{~d})-4(\mathrm{f})$.

3.5. GL Inhibits Autophagy-Related Protein in CisplatinInduced Nephrotoxicity. To elucidate whether GL played any role in autophagy-mediated nephrotoxicity in rats, the autophagy-related protein was analyzed using flow cytometry. As displayed in Figure 5, the accumulation of LC3 II was detected after CDDP treatment $352 \%$ as a percentage of the control group. This increment in autophagy-related protein was decreased by the administration of GL daily and EOD by $28 \%$ and $20 \%$, respectively. Moreover, IP injection with GL did not significantly decrease the LC3 II protein when compared to the CDDP group (Figure 5).

3.6. GL Downregulates the Epidermal Growth Factor (EGFR) Expression in Cisplatin-Treated Kidneys. Cisplatin injection caused marked 4.4-fold upregulation in EGFR renal expression as compared to that of the control group (Figures 6(c) and $6(\mathrm{~g}))$. Administration of GL daily and every other day downregulated the renal expression of EGFR to 0.3- and 0.38 -fold of the CDDP group, respectively, as shown in Figures 6(d), 6(e), and 6(g). However, GL inject. rats did not show any significant difference in renal EGFR expression when compared to the CDDP group (Figures 6(f) and 6(g)).

\section{Discussion}

Cisplatin is a highly effective antineoplastic drug, which is widely used in the treatment of several types of cancers, the second leading cause of global death. However, CDDP causes acute nephrotoxicity. Despite the use of adjuvant therapies, such as those with fluids and mannitol, nephrotoxicity remains a significant limiting factor, and novel adjuvant treatments need to be developed [16]. This study suggested the potential nephroprotective effect of GL against CDDPinduced acute nephrotoxicity in rats. Moreover, our study has a novelty in investigating the possible underlying mechanisms including its effect on the oxidative and inflammatory status as well as apoptosis. Moreover, the possible roles of autophagy and epidermal growth factor receptor downstream signaling pathways in CDDP-induced renal injury were also explored.

To induce acute nephrotoxicity in rats, CDDP was injected intraperitoneally as a single dose of $12 \mathrm{mg} / \mathrm{kg}$. Acute nephrotoxic damages were confirmed by increased levels of nephrotoxicity indices including BUN and serum creatinine as well as the histopathological changes. BUN and serum creatinine are known to accumulate in the blood when the kidneys fail to clear nitrogenous wastes as a result of extensive morphological damage and functional impairment [55]. Our findings confirmed those of previous studies [56-58]. Notably, the administration of GL had hampered the renal damages produced by CDDP, as evidenced by decreased BUN and serum creatinine levels. Also, histopathological examination showed complete restoration of the severe tubular dilation and epithelial degeneration induced by CDDP in the daily GL-treated group which was superior over the other two groups.

Besides nephrotoxicity indices, the possible mechanisms underlying the nephroprotective effects of GL were investigated. There are undeniable shreds of evidence that oxidative stress plays a pivotal role in the pathogenesis of CDDPinduced nephrotoxicity. It has been reported that the generation of reactive oxygen species (ROS) induced by CDDP promotes cellular damage $[59,60]$, apoptosis, and inflammation [61]. In this study, the CDDP-injected group showed serious oxidative stress in renal tissues indicated by SOD reduction and a marked increase in $\mathrm{H}_{2} \mathrm{O}_{2}$ as well as lipid peroxidation. These findings were in accordance with those demonstrated by previous studies [62, 63]. Pretreatment with GL normalized the levels of the oxidative markers in renal tissues compared to the CDDP group. Indeed, dietary antioxidants had been used to ameliorate the CDDP-induced renal injury in rats $[64,65]$. In addition to the oxidative stress, the role of inflammation in CDDP-induced nephrotoxicity is well documented. Cisplatin-induced cellular damage and necrosis lead to the release of damage-associated molecular pattern molecules, such as HMGB-1 [13], which bind to toll-like receptor (TLR) and induce inflammation through activation of the NF- $\kappa$ B pathway $[66,67]$. Our results showed that GL downregulated the HMGB-1/NF- $\kappa$ B signaling 


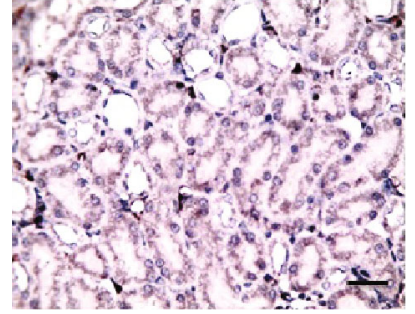

(a)

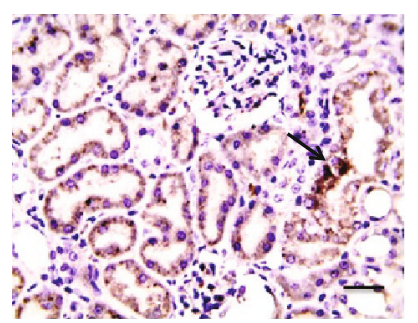

(d)

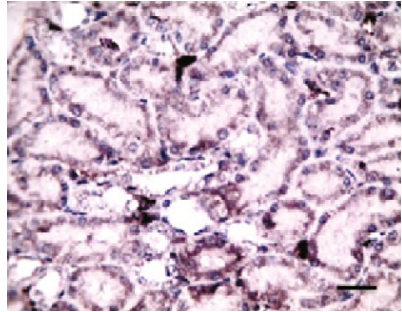

(b)

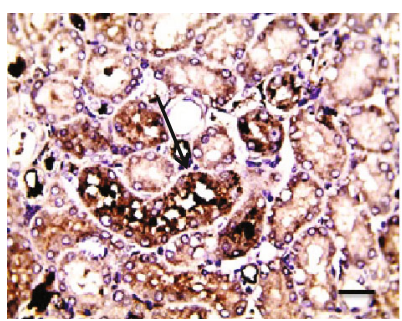

(e)

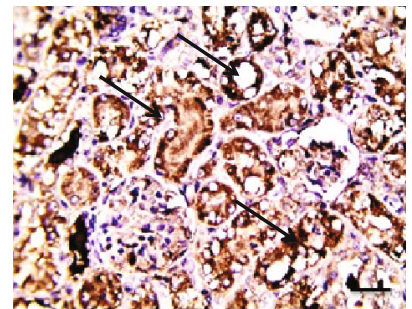

(c)

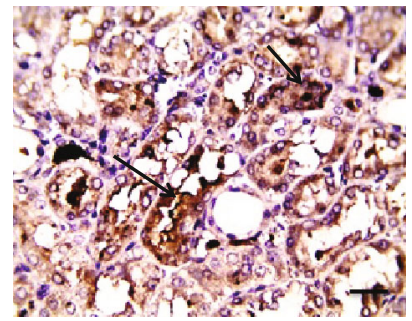

(f)

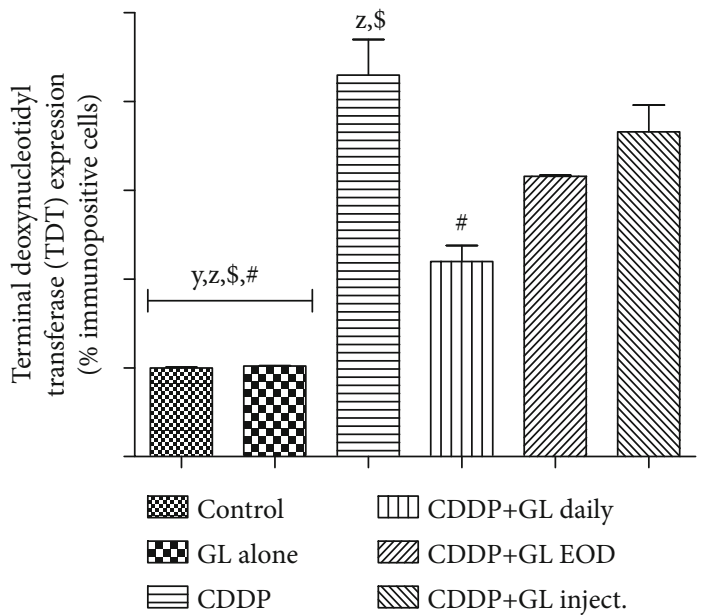

(g)

FIgURE 4: Immunohistochemical expression of terminal deoxynucleotidyl transferase (TDT). (a, b) The control and GL alone groups show very low positive stained cells. (c) The CDDP group shows very strong TDT-positive cells as indicated by intense brown color. (d) The CDDP+GL daily group shows mild TDT-positive stained cells. (e) The CDDP+GL EOD group shows moderate immunopositive stained cells as represented by positive calls. (f) The CDDP+GL inject. group shows strong TDT-positive cells with black arrows representing a high expression of TDT-positive cells. (g) Quantitative expression of TDT expressed as a percentage of immunopositive cells, values are given as mean \pm SEM $(n=6)$ for each group. ${ }^{\mathrm{X}} P<0.05$ compared to the control group, ${ }^{\mathrm{y}} P<0.05$ compared to the CDDP group, ${ }^{\mathrm{z}} P<0.05$ compared to the CDDP+GL daily group, ${ }^{\$} P<0.05$ compared to the CDDP+GL EOD group, and ${ }^{\#} P<0.05$ compared to the CDDP+GL inject. group using one-way ANOVA followed by Tukey Kramer as post hoc test. IHC counterstained with Mayer's hematoxylin. X: 400 bar 50. CDDP: cisplatin; GL: Ganoderma lucidum; EOD: every other day; TDT: terminal deoxynucleotidyl transferase.

pathway augmented by CDDP. Thus, we suggested that GL may have ameliorated the CDDP-induced AKI through inhibition of the HMGB-1/NF- $\kappa$ B-mediated inflammatory pathway.

Moreover, apoptosis and autophagy play crucial roles in AKI development; however, the exact pathogenesis of AKI induced by CDDP remains poorly understood. Counteracting effects of autophagy on cell survival and death have been documented, and it has been suggested that autophagy could promote cell survival only when there is an appropriate level of autophagy, while it mediates cell death when autophagy flux is very high [68]. Accordingly, we assessed the changes in LC3 II protein levels, a molecular marker of autophagy [69], and results showed marked promotion of LC3 II expressions in the CDDP group but were inhibited in GL-exposed rats. The $\mathrm{CDDP}+\mathrm{GL}$ daily group showed superior activity over both the EOD and inject. groups. However, it is still significantly higher than the control rats. Moreover, apoptosis is a programmed cell death that could be elicited by oxidative stress, inflammation, and many other factors, and it is controlled by the balance between the pro- and antiapoptotic genes [70]. Treatment with GL greatly reduced the expression of caspase- 3 and the number of TDT-positive renal cells which indicated that GL could ameliorate the CDDP- 

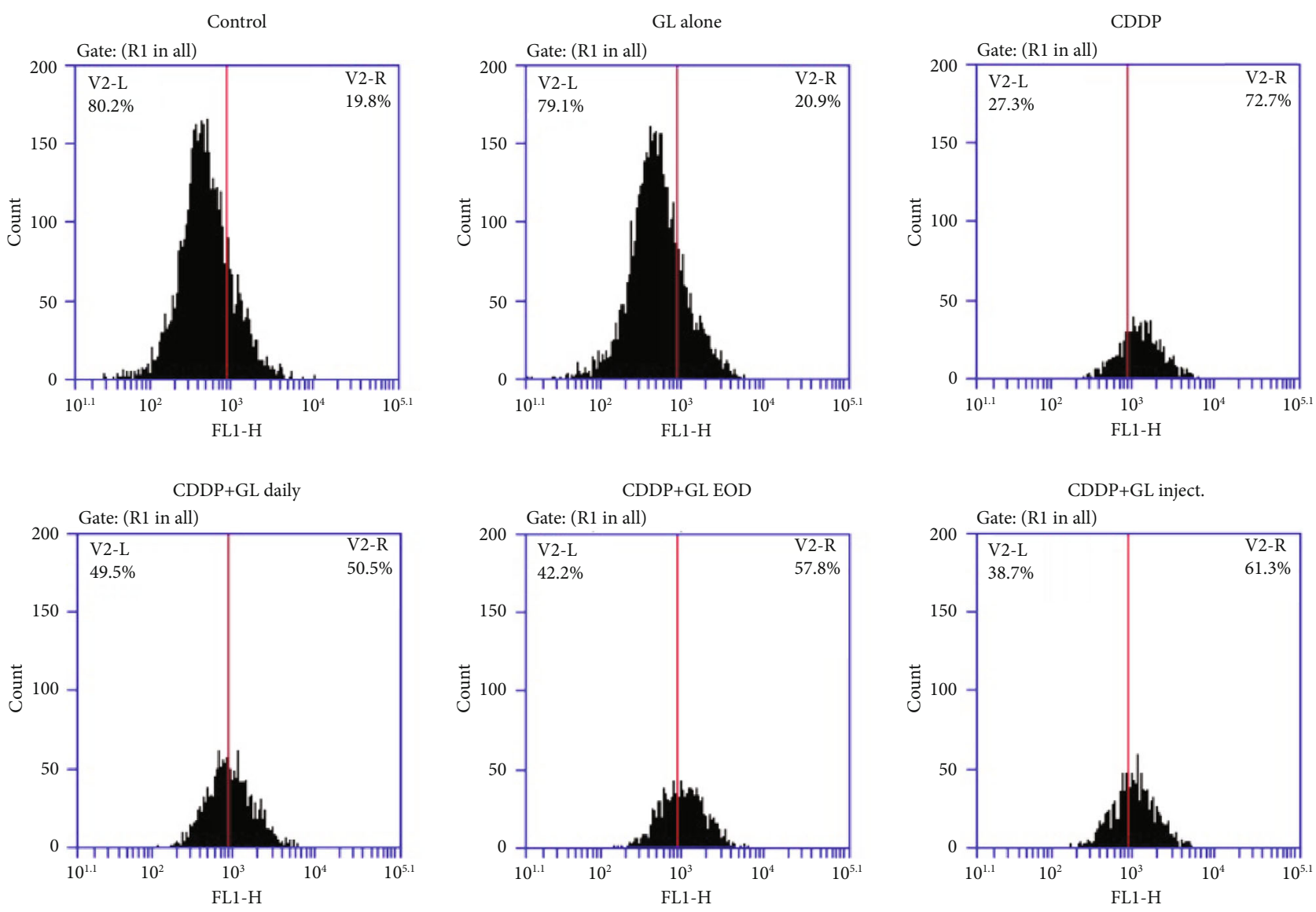

(a)

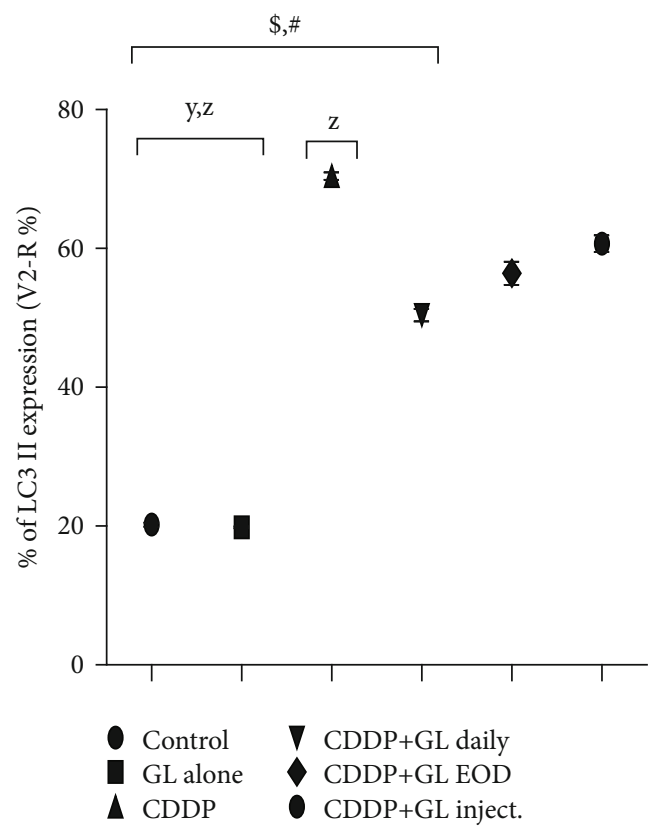

(b)

Figure 5: Effect of Ganoderma lucidum and cisplatin on the expression of LC3 II in kidney tissue by flow cytometry. (a) Photos from flow cytometry show different treatment groups of LC3 II expression in renal tissues. (b) Quantitative expression of LC3 II in different treatment groups as a percentage (V2-R\%); ${ }^{\mathrm{X}} \mathrm{P}<0.05$ compared to the control group, ${ }^{\mathrm{y}} \mathrm{P}<0.05$ compared to the CDDP group, ${ }^{\mathrm{z}} \mathrm{P}<0.05$ compared to the CDDP+GL daily group, ${ }^{\$} P<0.05$ compared to the $\mathrm{CDDP}+\mathrm{GL}$ EOD group, and ${ }^{\#} P<0.05$ compared to the CDDP+GL inject. group using one-way ANOVA followed by Tukey-Kramer as post hoc test. CDDP: cisplatin; GL: Ganoderma lucidum; EOD: every other day; LC3 II: microtubule-associated protein 1A/1B-light chain 3. 


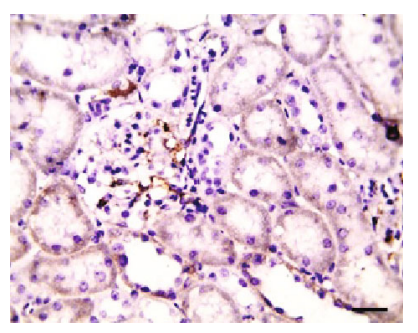

(a)

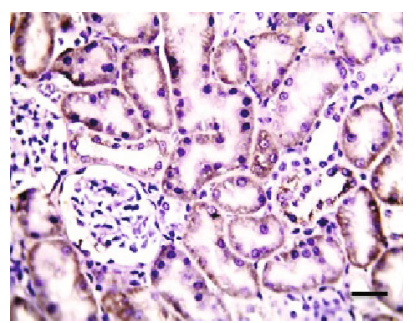

(d)

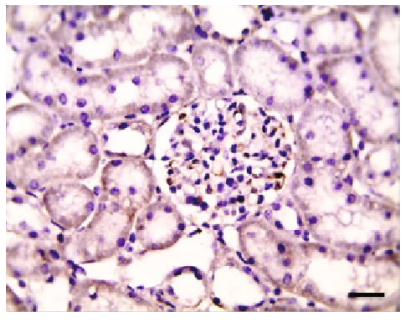

(b)

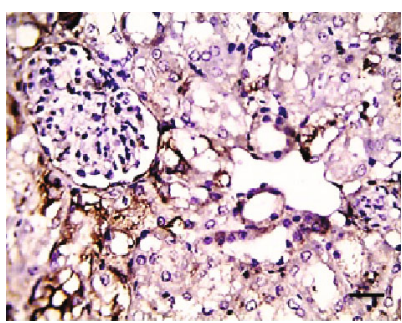

(e)

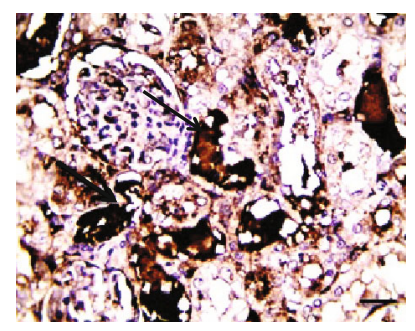

(c)

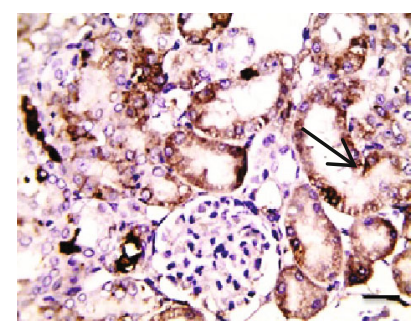

(f)

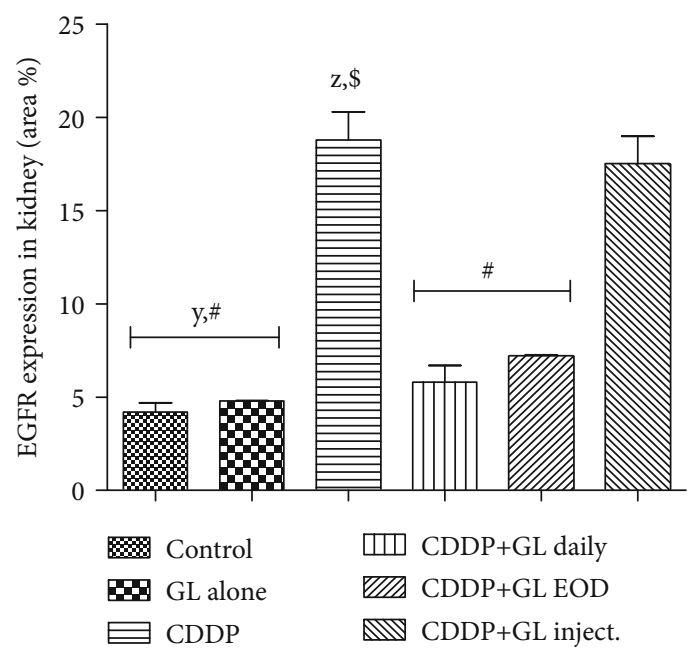

(g)

FIGURE 6: Expression of epidermal growth factor receptor (EGFR) by immunohistochemical staining. (a, b) The control and GL alone groups display a minimal expression of EGFR. (c) The cisplatin group displays an immense EGFR expression (brown staining). (d) The CDDP+GL daily group displays a limited EGFR expression. (e) The CDDP+GL EOD group displays a minimal EGFR expression. (f) The CDDP+GL inject. group displays EGFR expression. (g) Area percentage of immunopositive reaction. Values are given as mean \pm SEM $(n=6)$ for each group. ${ }^{\mathrm{X}} P<0.05$ compared to the control group, ${ }^{\mathrm{y}} P<0.05$ compared to the CDDP group, ${ }^{\mathrm{z}} P<0.05$ compared to the CDDP+GL daily group, ${ }^{\$} P<0.05$ compared to the CDDP+GL EOD group, and ${ }^{\#} P<0.05$ compared to the CDDP+GL inject. group using one-way ANOVA followed by Tukey-Kramer as post hoc test. IHC counterstained with Mayer's hematoxylin. X: 400 bar 5. CDDP: cisplatin; GL: Ganoderma lucidum; EOD: every other day; EGFR: epidermal growth factor receptor.

induced AKI through effective prevention of apoptosis in CDDP-exposed renal tissues as previously mentioned in cyclophosphamide-induced AKI [71]. Moreover, to further elucidate the proved complex interaction between autophagy and apoptosis in CDDP-induced nephrotoxicity [72], we noticed that the expressions of key apoptotic caspases, caspase-3, as well as TDT, were inhibited and accompanied by downregulation in autophagy-related protein, LC3 II, indicating that the occurrence of apoptosis may be regulated by autophagy. Furthermore, we suggested that CDDP caused excessive ROS production (high $\mathrm{H}_{2} \mathrm{O}_{2}$ levels) where antioxidants such as SOD would be consumed destroying the bal- ance between ROS and antioxidant systems leading to autophagy-mediated apoptosis. Kang et al. [71] have documented that the combined action of oxidative stress imbalance and autophagy defects causes abnormal cell apoptosis which leads to the occurrence of AKI [71].

Indeed, it is undeniable that the disruption of growth factors and their receptors play a role in CDDP-induced renal injuries [56]. In renal proximal tubular cells, CDDP also activated the EGFR, which is involved in cell death rather than survival under these conditions [73]. EGFR may mediate renal injury by induction of inflammatory factors and cell apoptosis. However, inhibition of EGFR showed therapeutic 
potential for AKI during endotoxemia and diabetic nephropathy $[74,75]$. Our results showed that the upregulation of EGFR, following CDDP injection, was significantly downregulated in rats treated with GL, and this correction was associated with the improvement that occurred in nephrotoxicity indices. Our results were in accordance with a previous study which showed that erlotinib would protect against CDDPinduced AKI through inhibition of the EGFR-Akt signaling pathway [34]. Therefore, we suggested that GL protection against CDDP-induced nephrotoxicity might be through inhibition of the downstream signaling of EGFR. Furthermore, some studies reported that the EGFR blockade may also indirectly protect against diabetic nephropathy by increasing islet prosurvival autophagy activity [74]. In this current study, we found that EGFR signaling blockade by GL was accompanied by a significant reduction in the procell death persistent autophagy and apoptosis induced by CDDP; however, this autophagy activity was still higher than that in the control group. This means that GL may have inhibited the EGFR signaling, which in turn would inhibit the high autophagy flux augmented by CDDP; however, GL remained the appropriate prosurvival autophagy activity to guard against CDDP-induced cell death. Further investigations are clearly warranted to deeply elaborate the interrelationship between the inhibition of autophagy-mediated apoptosis and EGFR signaling. Finally, no studies have reported a decrease in CDDP chemotherapeutic effect in patients that concomitantly received GL extract; however, a very recent study has reported that GL extracts may sensitize cancer cells to conventional chemotherapeutics [76]. The present study supports further those clinical studies on GL and suggested some molecular mechanisms whereby GL would protect from CDDP-induced nephrotoxicity.

\section{Conclusion}

Taken together, the results of the current study suggested that GL might have a renoprotective effect in acute nephrotoxicity induced by CDDP. This effect might be attributed to the antioxidant, anti-inflammatory effect, and attenuation of autophagy-mediated apoptosis in renal tissues, and it has coincided with inhibition of the HMGB-1/NF- $\kappa$ B and EGFR signaling pathways. Additionally, we concluded that daily administration of GL was superior in the postulated renoprotective effects over both the EOD group and the inject. group. Furthermore, GL could be considered as a renoprotective natural compound in CDDP-induced kidney injury, although further studies are required to confirm its beneficial effects in patients. However, it has been proved that GL does not affect the anticancer potential of CDDP.

\section{Abbreviations}

CDDP: Cisplatin

GL: Ganoderma lucidum

SOD: $\quad$ Superoxide dismutase

ROS: $\quad$ Reactive oxygen species

EGFR: Epidermal growth factor receptor

HMGB-1: High-mobility group box-1
NF- $\kappa$ B: $\quad$ Nuclear factor kappa B

LC3 II: Microtubule-associated protein 1A/1B-light

chain 3

TDT: Terminal deoxynucleotidyl transferase.

\section{Data Availability}

All data generated or analyzed during this study are included in this published article.

\section{Conflicts of Interest}

The authors declare that there are no conflicts of interest.

\section{Authors' Contributions}

All authors equally contributed to the work.

\section{Acknowledgments}

This research was funded by the Deanship of Scientific Research at Princess Nourah bint Abdulrahman University through the Fast-track Research Funding Program.

\section{References}

[1] B. Rosenberg, "Platinum complexes for the treatment of cancer: why the search goes on," in Cisplatin: Chemistry and Biochemistry of a Leading Anticancer Drug, B. Lippert, Ed., pp. 327, Wiley-VCH, Basel, Switzerland, 1999.

[2] E. E. Vokes, "Induction chemotherapy for head and neck cancer: recent data," Oncologist, vol. 15, Suppl 3, pp. 3-7, 2010.

[3] D. S. Alberts, P. Y. Liu, E. V. Hannigan et al., "Intraperitoneal cisplatin plus intravenous cyclophosphamide versus intravenous cisplatin plus intravenous cyclophosphamide for stage III ovarian cancer," The New England Journal of Medicine, vol. 335, no. 26, pp. 1950-1955, 1996.

[4] N. Ismaili, M. Amzerin, and A. Flechon, "Chemotherapy in advanced bladder cancer: current status and future," Journal of Hematology \& Oncology, vol. 4, no. 1, 2011.

[5] J. Gronwald, T. Byrski, J. Lubinski, and S. A. Narod, "Cisplatin in breast cancer treatment in BRCA1 carriers," Hereditary Cancer in Clinical Practice, vol. 10, Suppl 4, pp. A17-4287, 2012.

[6] A. Ozkok and C. L. Edelstein, "Pathophysiology of cisplatininduced acute kidney injury," BioMed Research International, vol. 2014, Article ID 967826, 17 pages, 2014.

[7] N. A. G. Santos, C. S. Catão, N. M. Martins, C. Curti, M. L. P. Bianchi, and A. C. Santos, "Cisplatin-induced nephrotoxicity is associated with oxidative stress, redox state unbalance, impairment of energetic metabolism and apoptosis in rat kidney mitochondria," Archives of Toxicology, vol. 81, no. 7, pp. 495-504, 2007.

[8] R. P. Miller, R. K. Tadagavadi, G. Ramesh, and W. B. Reeves, "Mechanisms of cisplatin nephrotoxicity," Toxins, vol. 2, no. 11, pp. 2490-2518, 2010.

[9] J. A. Winston and R. Safirstein, "Reduced renal blood flow in early cisplatin-induced acute renal failure in the rat," American Journal of Physiology-Renal Physiology, vol. 249, no. 4, pp. F490-F496, 1985. 
[10] Y. Chen, D. Brott, W. Luo et al., "Assessment of cisplatininduced kidney injury using an integrated rodent platform," Toxicology and Applied Pharmacology, vol. 268, no. 3, pp. 352-361, 2013.

[11] M. Naziroglu, A. Karaoglu, and A. O. Aksoy, "Selenium and high dose vitamin $\mathrm{E}$ administration protects cisplatininduced oxidative damage to renal, liver and lens tissues in rats," Toxicology, vol. 195, no. 2-3, pp. 221-230, 2004.

[12] H. Yilmaz, M. Iraz, S. Sogut et al., "The effects of erdosteine on the activities of some metabolic enzymes during cisplatininduced nephrotoxicity in rats," Pharmacological Research, vol. 50, no. 3, pp. 287-290, 2004.

[13] J. Kim, "Poly(ADP-ribose) polymerase activation induces high mobility group box 1 release from proximal tubular cells during cisplatin nephrotoxicity," Physiological Research, vol. 65, no. 2, pp. 333-340, 2016.

[14] N. Pabla and Z. Dong, "Cisplatin nephrotoxicity: mechanisms and renoprotective strategies," Kidney International, vol. 73, no. 9 , pp. 994-1007, 2008.

[15] M. Jiang, Q. Wei, J. Wang et al., "Regulation of PUMA- $\alpha$ by p53 in cisplatin-induced renal cell apoptosis," Oncogene, vol. 25, no. 29, pp. 4056-4066, 2006.

[16] Z. Herrera-Perez, N. Gretz, and H. Dweep, “A comprehensive review on the genetic regulation of cisplatin-induced nephrotoxicity," Current Genomics, vol. 17, no. 3, pp. 279-293, 2016.

[17] T. V. Dupre, M. A. Doll, P. P. Shah et al., "Suramin protects from cisplatin-induced acute kidney injury," American Journal of Physiology-Renal Physiology, vol. 310, no. 3, pp. F248-F258, 2016.

[18] R. Karwasra, P. Kalra, Y. K. Gupta, D. Saini, A. Kumar, and S. Singh, "Antioxidant and anti-inflammatory potential of pomegranate rind extract to ameliorate cisplatin-induced acute kidney injury," Food \& Function, vol. 7, no. 7, pp. 3091-3101, 2016.

[19] S. A. Wahdan, S. S. Azab, D. A. Elsherbİny, and E. el-demerdash, "Piceatannol ameliorates cisplatin-induced histological and biochemical alterations in rats kidney," International Journal of Pharmacy and Pharmaceutical Sciences, vol. 9, no. 10, p. 305, 2017

[20] L. F. Li, H. B. Liu, Q. W. Zhang et al., "Comprehensive comparison of polysaccharides from Ganoderma lucidum and $G$. sinense: chemical, antitumor, immunomodulating and gutmicrobiota modulatory properties," Scientific Reports, vol. 8, no. 1, p. 6172, 2018.

[21] N. Sheena, T. A. Ajith, A. Mathew, and K. K. Janardhanan, "Antibacterial activity of three Macrofungi,Ganoderma lucidum,Navesporus floccosaandPhellinus rimosusOccurring in south India," Pharmaceutical Biology, vol. 41, no. 8, pp. 564$567,2008$.

[22] X. Teng, W. Zhang, Y. Song, H. Wang, M. Ge, and R. Zhang, "Protective effects of Ganoderma lucidum triterpenoids on oxidative stress and apoptosis in the spleen of chickens induced by cadmium," Environmental Science and Pollution Research International, vol. 26, no. 23, pp. 23967-23980, 2019.

[23] S. F. Shen, L. F. Zhu, Z. Wu, G. Wang, Z. Ahmad, and M. W. Chang, "Production of triterpenoid compounds fromGanoderma lucidumspore powder using ultrasound-assisted extraction," Preparative Biochemistry \& Biotechnology, vol. 50, no. 3, pp. 302-315, 2020.

[24] P. T. Tran, N. T. Dat, N. H. Dang et al., "Ganomycin I from Ganoderma lucidum attenuates RANKL-mediated osteoclas- togenesis by inhibiting MAPKs and NFATc1," Phytomedicine : international journal of phytotherapy and phytopharmacology, vol. 55, pp. 1-8, 2019.

[25] P. Zeng, Z. Guo, X. Zeng et al., "Chemical, biochemical, preclinical and clinical studies of Ganoderma lucidum polysaccharide as an approved drug for treating myopathy and other diseases in China," Journal of Cellular and Molecular Medicine, vol. 22, no. 7, pp. 3278-3297, 2018.

[26] B. Boh, M. Berovic, J. Zhang, and L. Zhi-Bin, "Ganoderma lucidum and its pharmaceutically active compounds," Biotechnology Annual Review, vol. 13, pp. 265-301, 2007.

[27] B. Sanodiya, G. Thakur, R. Baghel, G. Prasad, and P. Bisen, "Ganoderma lucidum: a potent pharmacological macrofungus," Current Pharmaceutical Biotechnology, vol. 10, no. 8, pp. 717-742, 2009.

[28] D. Zhong, H. Wang, M. Liu et al., "Ganoderma lucidum polysaccharide peptide prevents renal ischemia reperfusion injury via counteracting oxidative stress," Scientific Reports, vol. 5, no. $1,2015$.

[29] D. Pan, D. Zhang, J. Wu et al., "A novel proteoglycan from Ganoderma lucidum fruiting bodies protects kidney function and ameliorates diabetic nephropathy via its antioxidant activity in C57BL/6 db/db mice," Food and Chemical Toxicology, vol. 63, pp. 111-118, 2014.

[30] Y. M. Yan, X. L. Wang, L. L. Zhou et al., "Lingzhilactones from Ganoderma lingzhi ameliorate adriamycin-induced nephropathy in mice," Journal of Ethnopharmacology, vol. 176, pp. 385393, 2015.

[31] T. G. Pillai, M. John, and G. Sara Thomas, "Prevention of cisplatin induced nephrotoxicity by terpenes isolated from Ganoderma lucidum occurring in Southern Parts of India," Experimental and Toxicologic Pathology, vol. 63, no. 1-2, pp. 157-160, 2011.

[32] J. H. Kim, D. J. Park, J. C. Yun et al., "Human adipose tissue-derived mesenchymal stem cells protect kidneys from cisplatin nephrotoxicity in rats," American Journal of Physiology-Renal Physiology, vol. 302, no. 9, pp. F1141F1150, 2012.

[33] S. Periyasamy-Thandavan, M. Jiang, Q. Wei, R. Smith, X. M. Yin, and Z. Dong, "Autophagy is cytoprotective during cisplatin injury of renal proximal tubular cells," Kidney International, vol. 74, no. 5, pp. 631-640, 2008.

[34] Y. Wada, M. Iyoda, K. Matsumoto et al., "Epidermal growth factor receptor inhibition with erlotinib partially prevents cisplatin-induced nephrotoxicity in rats," PLoS One, vol. 9, no. 11, article e111728, 2014.

[35] E. Henson, Y. Chen, and S. Gibson, "EGFR family members' regulation of autophagy is at a crossroads of cell survival and death in cancer," Cancers, vol. 9, no. 12, p. 27, 2017.

[36] D. Cor, Z. Knez, and M. Knez Hrncic, “Antitumour, antimicrobial, antioxidant and antiacetylcholinesterase effect of Ganoderma lucidum terpenoids and polysaccharides: a review," Molecules, vol. 23, no. 3, p. 649, 2018.

[37] G. S. Wu, J. J. Guo, J. L. Bao et al., "Anti-cancer properties of triterpenoids isolated from Ganoderma lucidum - a review," Expert Opinion on Investigational Drugs, vol. 22, no. 8, pp. 981-992, 2013.

[38] J.-Y. Lin and C.-Y. Tang, "Determination of total phenolic and flavonoid contents in selected fruits and vegetables, as well as their stimulatory effects on mouse splenocyte proliferation," Food Chemistry, vol. 101, no. 1, pp. 140-147, 2007. 
[39] C. C. Chang, M. H. Yang, H. M. Wen, and J. C. Chern, "Estimation of total flavonoid content in propolis by two complementary colorimetric methods," Journal of Food and Drug Analysis, vol. 10, pp. 178-182, 2002.

[40] E. A. Lissi, B. Modak, R. Torres, J. Escobar, and A. Urzua, "Total antioxidant potential of resinous exudates fromHeliotropiumspecies, and a comparison of the ABTS and DPPH methods," Free Radical Research, vol. 30, no. 6, pp. 471-477, 2009.

[41] R. Purena, R. Seth, and R. Bhatt, "Protective role of Emblica officinalis hydro-ethanolic leaf extract in cisplatin induced nephrotoxicity in Rats," Toxicology Reports, vol. 5, pp. 270277, 2018.

[42] N. Sheena, T. Ajith, and K. Janardhanan, "Prevention of nephrotoxicity induced by the anticancer drug cisplatin, using Ganoderma lucidum, a medicinal mushroom occurring in South India," Current Science, vol. 85, 2003.

[43] M. F. Ahmad, "Ganoderma lucidum: persuasive biologically active constituents and their health endorsement," Biomedicine \& Pharmacotherapy, vol. 107, pp. 507-519, 2018.

[44] Ö. Hüseyin, İ. Sevgi, D. Engin, A. Frrat, P. Gülsüm, and D. Şenay, "Ganoderma lucidum protects rat brain tissue against trauma-induced oxidative stress," Korean Journal of Neurotrauma, vol. 13, no. 2, pp. 76-84, 2017.

[45] J. D. Banchroft, A. Stevens, and D. R. Turner, Theory and Practice of Histological Techniques, Churchil Livingstone, New York, London, San Francisco, Tokyo, fourth ed. edition, 1996.

[46] A. Weidemann, W. M. Bernhardt, B. Klanke et al., "HIF activation protects from acute kidney injury," Journal of the American Society of Nephrology: JASN, vol. 19, no. 3, pp. 486-494, 2008.

[47] T. C. Fang, M. R. Alison, H. T. Cook, R. Jeffery, N. A. Wright, and R. Poulsom, "Proliferation of bone marrowderived cells contributes to regeneration after folic acidinduced acute tubular injury," Journal of the American Society of Nephrology : JASN, vol. 16, no. 6, pp. 17231732, 2005.

[48] A. L. Chaney and E. P. Marbach, "Modified reagents for determination of urea and ammonia," Clinical Chemistry, vol. 8, no. 2, pp. 130-132, 1962.

[49] J. Schirmeister, H. Willmann, and H. Kiefer, "Kritische Beurteilung des Plasmakreatinins als test des Glomerulusfiltrates," Verhandlungen der Deutschen Gesellschaft für Innere Medizin, vol. 70, pp. 678-681, 1964.

[50] H. Aebi, "[13] Catalase in vitro," Methods in Enzymology, vol. 105, pp. 121-126, 1984.

[51] L. R. DeChatelet, C. E. McCall, L. C. McPhail, and R. B. Johnston Jr., "Superoxide dismutase activity in leukocytes," The Journal of Clinical Investigation, vol. 53, no. 4, pp. 11971201, 1974.

[52] H. Hassan, M. al-Gayyar, A. el-Gayar, and T. Ibrahim, "Effect of simvastatin on inflammatory cytokines balance in air pouch granuloma model," Inflammation \& Allergy Drug Targets, vol. 13, no. 1, pp. 74-79, 2014.

[53] E. Shvets and Z. Elazar, "Chapter 9 flow cytometric analysis of autophagy in living mammalian cells," in Methods in enzymology, vol. 452, pp. 131-141, Academic Press, 2009.

[54] E. Shvets, E. Fass, and Z. Elazar, "Utilizing flow cytometry to monitor autophagy in living mammalian cells," Autophagy, vol. 4, no. 5, pp. 621-628, 2008.
[55] Q. Wei, M. H. Wang, and Z. Dong, "Differential gender differences in ischemic and nephrotoxic acute renal failure," American Journal of Nephrology, vol. 25, no. 5, pp. 491-499, 2005.

[56] R. N. El-Naga and Y. F. Mahran, "Indole-3-carbinol protects against cisplatin-induced acute nephrotoxicity: role of calcitonin gene-related peptide and insulin-like growth factor-1," Scientific Reports, vol. 6, no. 1, 2016.

[57] M. Nematbakhsh, F. Ashrafi, H. Nasri et al., "A model for prediction of cisplatin induced nephrotoxicity by kidney weight in experimental rats," Journal of Research in Medical Sciences: The Official Journal of Isfahan University of Medical Sciences, vol. 18, no. 5, pp. 370-373, 2013.

[58] Y. F. Mahran, "New insights into the protection of growth hormone in cisplatin-induced nephrotoxicity: the impact of IGF-1 on the Keap1-Nrf2/HO-1 signaling," Life Sciences, vol. 253, p. 117581, 2020.

[59] R. Marullo, E. Werner, N. Degtyareva et al., "Cisplatin induces a mitochondrial-ROS response that contributes to cytotoxicity depending on mitochondrial redox status and bioenergetic functions," PLoS One, vol. 8, no. 11, article e81162, 2013.

[60] I. Gulcin, "Antioxidant activity of food constituents: an overview," Archives of Toxicology, vol. 86, no. 3, pp. 345-391, 2012.

[61] T. Gomez-Sierra, D. Eugenio-Perez, A. Sanchez-Chinchillas, and J. Pedraza-Chaverri, "Role of food-derived antioxidants against cisplatin induced-nephrotoxicity," Food and chemical toxicology: an international journal published for the British Industrial Biological Research Association, vol. 120, pp. 230242, 2018.

[62] W. Arjumand and S. Sultana, "Glycyrrhizic acid: A phytochemical with a protective role against cisplatin- induced genotoxicity and nephrotoxicity," Life Sciences, vol. 89, no. 13-14, pp. 422-429, 2011.

[63] R. N. El-Naga, "Pre-treatment with cardamonin protects against cisplatin-induced nephrotoxicity in rats: impact on NOX-1, inflammation and apoptosis," Toxicology and Applied Pharmacology, vol. 274, no. 1, pp. 87-95, 2014.

[64] Y. Shimeda, Y. Hirotani, Y. Akimoto et al., "Protective effects of capsaicin against cisplatin-induced nephrotoxicity in rats," Biological \& Pharmaceutical Bulletin, vol. 28, no. 9, pp. 1635-1638, 2005.

[65] R. Rezaee, A. A. Momtazi, A. Monemi, and A. Sahebkar, "Curcumin: a potentially powerful tool to reverse cisplatin-induced toxicity," Pharmacological Research, vol. 117, pp. 218-227, 2017.

[66] J. S. Roh and D. H. Sohn, "Damage-associated molecular patterns in inflammatory diseases," Immune Network, vol. 18, no. 4, article e27, 2018.

[67] J. R. Klune, R. Dhupar, J. Cardinal, T. R. Billiar, and A. Tsung, "HMGB1: endogenous danger signaling," Molecular Medicine, vol. 14, no. 7-8, pp. 476-484, 2008.

[68] B. Levine, “Autophagy and cancer," Nature, vol. 446, no. 7137, pp. 745-747, 2007.

[69] B. Cheng, J. Lu, T. Li et al., "1,3-Dichloro-2-propanol inhibits autophagy via P53/AMPK/mTOR pathway in HepG2 cells," Food and Chemical Toxicology: an international journal published for the British Industrial Biological Research Association, vol. 122, pp. 143-150, 2018.

[70] O. F. X. Almeida, G. L. Condé, C. Crochemore et al., "Subtle shifts in the ratio between pro- and antiapoptotic molecules after activation of corticosteroid receptors decide neuronal fate," FASEB Journal : Official Publication of the Federation 
of American Societies for Experimental Biology, vol. 14, no. 5, pp. 779-790, 2000.

[71] X. Kang, M. Jing, G. Zhang, L. He, P. Hong, and C. Deng, “The ameliorating effect of plasma protein from Tachypleus tridentatus on cyclophosphamide-induced acute kidney injury in mice," Marine Drugs, vol. 17, no. 4, p. 227, 2019.

[72] W. P. Roos, A. D. Thomas, and B. Kaina, "DNA damage and the balance between survival and death in cancer biology," Nature Reviews Cancer, vol. 16, no. 1, pp. 20-33, 2016.

[73] I. Arany, J. K. Megyesi, H. Kaneto, P. M. Price, and R. L. Safirstein, "Cisplatin-induced cell death is EGFR/src/ERK signaling dependent in mouse proximal tubule cells," American Journal of Physiology-Renal Physiology, vol. 287, no. 3, pp. F543-F549, 2004.

[74] Z. Li, Y. Li, J. M. Overstreet et al., "Inhibition of epidermal growth factor receptor activation is associated with improved diabetic nephropathy and insulin resistance in type 2 diabetes," Diabetes, vol. 67, no. 9, pp. 1847-1857, 2018.

[75] X. Xu, J. Wang, R. Yang, Z. Dong, and D. Zhang, "Genetic or pharmacologic inhibition of EGFR ameliorates sepsisinduced AKI," Oncotarget, vol. 8, no. 53, pp. 91577-91592, 2017.

[76] A. Opattova, J. Horak, S. Vodenkova et al., "Ganoderma Lucidum induces oxidative DNA damage and enhances the effect of 5-Fluorouracil in colorectal cancer in vitro and in vivo," Mutation Research/Genetic Toxicology and Environmental Mutagenesis, vol. 845, p. 403065, 2019. 